\title{
Reuniones de vecinos Participación y regulación moral en la ciudad de Buenos Aires gobernada por el PRO
}

Joaquín Alberto Oscar Coto ${ }^{1}$

${ }^{1}$ Sección de Antropología Social, Instituto de Ciencias Antropológicas, Universidad de Buenos Aires. ORCiD: 0000-0002-6603-2553

Correo electrónico: cotojao@gmail.com

\section{Recibido}

diciembre de 2019

Aceptado

abril de 2020

doi: $10.34096 /$ cas.i52.6541

\section{Resumen}

Las reuniones de vecinos son encuentros organizados por el área de Participación Ciudadana del Gobierno de la Ciudad de Buenos Aires en los cuales el jefe de Gobierno porteño acude a un barrio para dialogar con los vecinos. En estos eventos se ponen en juego formas específicas de producir la participación y se define a los vecinos como comunidad de referencia para las políticas de gobierno. Así, analizaré la participación promovida por el gobierno del PRO en CABA entendiendo las reuniones de vecinos como procedimientos por los que se realiza una "regulación moral" que normaliza formas específicas de gobierno, participación y ciudadanía. A su vez, retomaré aspectos de la construcción de la identidad partidaria del PRO. Para la realización de este artículo desarrollé trabajo de campo etnográfico en los eventos de participación de una comuna porteña, entre marzo de 2016 y julio de 2017, y entrevistas a funcionarios.

\section{Neighbors' meetings: participation and moral regulation in the city of Buenos Aires governed by the PRO}

\footnotetext{
Abstract

"Neighbors' meetings" are events organized by the Buenos Aires City Government (GCBA) during which the mayor talks to local residents in a specific neighborhood. Particular ways of producing 'participation' take place during these events, and "neighbors" are defined as a community of reference that will orientate governmental policies, both through discursive and non-discursive practices. This paper thus analyzes "Neighbors' meetings" in the city of Buenos Aires in order to understand the meanings of 'participation', as fostered by GCBA, and how it works as a "moral regulation" device. In addition, the article seeks to clarify how the political identity of the ruling PRO party permeates it's participatory initiatives. As a consequence, we will also refer to other
}

\section{Palabras clave}

Participación Ciudadana; Ciudadanía; PRO; Vecinos; Políticas Públicas

\section{Key words}

Citizen Participation; Citizenship; PRO; Neighbors; Public Policies 
Palavras-chave

Participação cidadã; Cidadania; PRO; Vizinho; Políticas públicas participatory policies by the GCBA. This article is based on ethnographic fieldwork carried out in a Buenos Aires district [comuna] between March 2016 and July 2017 as well as on interviews with public officials.

\section{Reuniões de vizinhos: participação e regulação moral na Cidade de Buenos Aires governada pelo PRO}

\section{Resumo}

As "Reuniões de vizinhos" são eventos organizados pela área de Participação Cidadã do Governo da Cidade de Buenos Aires, nas quais o Chefe de Governo visita os diferentes bairros da Cidade para falar com seus habitantes. Nesses eventos o governo movimenta formas específicas de produzir a participação, e define aos vizinhos como uma comunidade de referência para as políticas governamentais. Assim, vamos analisar a participação promovida pelo governo do PRO em Buenos Aires entendendo as Reuniões de Vizinhos como procedimentos nos quais é feita uma "regulação moral" que normaliza certas formas de governo, participação e cidadania. Ainda, vamos considerar as características da construção da identidade do partido PRO. Para a realização desse artigo desenvolvemos um trabalho de campo etnográfico nos eventos de participação de um distrito de Buenos Aires entre março de 2016 y julho de 2017, assim como entrevistas com funcionários.

\section{Introducción}

En el presente artículo analizaré las formas de participación impulsadas por el Gobierno de la Ciudad de Buenos Aires (GCBA) como prácticas por las cuales se realiza una "regulación moral", esto es, se definen las formas e imágenes aceptables de la actividad social y de la identidad individual y colectiva (Corrigan y Sayer, 2007). Específicamente, me enfocaré en las reuniones de vecinos. Esta elección radica en que estos eventos sintetizan muchas características también presentes en otros programas de participación del GCBA. Además, como se verá, tienen especial relevancia para las autoridades porteñas.

En los procesos de "regulación moral", los discursos y las prácticas no discursivas se articulan normalizando ciertas formas particulares de orden social. Ello tiene "consecuencias en cómo la gente concibe su identidad $\mathrm{y}$, en muchos casos, cómo debe concebirla y en cómo identifica 'su lugar' en el mundo" (Corrigan y Sayer, 2007, p. 45).

Concretamente, considero que mediante la participación impulsada por el GCBA se producen y normalizan formas específicas de participación, de gobierno -y de la relación entre gobernantes y gobernados- y se define una comunidad de referencia específica para las políticas gubernamentales. Para el análisis retomaré aspectos de la construcción de la identidad partidaria del PRO, ligada a la racionalidad política de este partido.

A su vez, también haré una referencia breve a otros programas participativos del GCBA. Ello permitirá contextualizar relativamente las reuniones de vecinos y resaltar cómo las lógicas de estas son comunes a otras de las iniciativas del GCBA. 
Es importante señalar que no partiré de una definición previa de lo que es la participación sino que ésta será entendida según es producida en las prácticas consideradas.

Este trabajo es fruto de la investigación realizada para mi tesis de licenciatura en antropología social. Para ella realicé trabajo de campo etnográfico en los eventos de participación ciudadana de la Comuna 6 (barrio de Caballito) ${ }^{1}$ entre marzo de 2016 y julio de 2017, y cuatro entrevistas a funcionarios y "participantes". A su vez, también trabajé sobre fuentes tales como el sitio oficial de Participación Ciudadana y las redes sociales de dicha área y del jefe y vicejefe de Gobierno porteño.

Por motivos de extensión y foco, aquí no abordaré las formas de participación existentes a nivel comunal ni el proceso de descentralización porteño, aspectos clave para una mirada más comprehensiva del rol de la participación en las disputas políticas de la CABA. ${ }^{2}$ A su vez, el artículo se centrará en la política del GCBA antes que en la recepción de los vecinos a estos eventos.

\section{Reuniones de vecinos: un sello de la gestión Rodríguez Larreta}

En 2009, durante la primera gestión de Mauricio Macri como jefe de gobierno de CABA, su entonces jefe de gabinete, Horacio Rodríguez Larreta, comenzó a realizar encuentros en los que "dialogaba" con los vecinos en forma itinerante por los distintos barrios porteños. Al lograr éste la Jefatura de Gobierno de la ciudad en 2015, las reuniones de vecinos -nombre dado a estos encuentros- pasaron a tener mayor frecuencia, trascendencia y recursos.

Para comenzar, cabe apuntar que no existe ninguna regulación que defina qué son, cómo funcionan y qué competencias tienen estas reuniones. Esta práctica es realizada continuamente en distintas comunas por el área de Participación Ciudadana del GCBA y funciona exclusivamente de acuerdo con las decisiones del Poder Ejecutivo porteño.

Tanto el jefe como el vicejefe de gobierno -Horacio Rodríguez Larreta y Diego Santilli, respectivamente- concurren de manera alternada a las reuniones de vecinos en los distintos barrios de CABA. También lo hacen otras figuras relevantes del GCBA, como el jefe de Gabinete, Felipe Miguel, o el presidente del Instituto de Vivienda de la Ciudad, Juan Maquieyra.

Cuadro 1. Cantidad de Reuniones de Vecinos protagonizadas por las autoridades de la CABA entre 2016-2019

\begin{tabular}{|l|c|c|c|c|}
\cline { 2 - 5 } \multicolumn{1}{c|}{} & $\mathbf{2 0 1 6}$ & $\mathbf{2 0 1 7}$ & $\mathbf{2 0 1 8}$ & $\mathbf{2 0 1 9}$ \\
\hline Rodríguez Larreta & 87 & 82 & 127 & 75 \\
\hline Santilli & 44 & 61 & 57 & 8 \\
\hline Otros funcionarios & 0 & 13 & 91 & 59 \\
\hline Total & 131 & 156 & 276 & 142 \\
\hline
\end{tabular}

Fuente: Elaboración del autor en base a información del sitio oficial de Participación Ciudadana
1. Para hacer una mínima contextualización, cabe señalar que los indicadores socioeconómicos de la Comuna 6 son, todos ellos, más favorables que en la media de la ciudad (Dirección General de Estadísticas y Censos de la Ciudad de Buenos Aires, 2019). A su vez, es una comuna en la que el PRO y Rodríguez Larreta suelen recibir apoyo en las elecciones. Por ejemplo, en las elecciones de 2019, como candidato a jefe de Gobierno, este último obtuvo casi el $58 \%$ de los votos de los habitantes de Caballito.

2. Para un análisis más amplio de las Reuniones de vecinos y un abordaje relacional de la participación impulsada por el GCBA y la participación comunal ver Coto (2018). 
3. Parece razonable deducir que la marcada disminución en la cantidad de reuniones en 2019 tuvo que ver con el proceso electoral: no hubo Reuniones de vecinos desde mediados de julio hasta fines de octubre, período en que tuvieron

lugar las elecciones primarias y generales a nivel local y nacional.

Además, la merma es especialmente acentuada en el caso de las reuniones con Santilli, lo que puede tener relación con que este asumiera el Ministerio de Justicia y Seguridad de CABA a fines de 2018.

4. El actual secretario de Atención y Gestión Ciudadana (a la cual pertenece Participación Ciudadana) moderaba las reuniones de vecinos con Rodríguez Larreta antes de que este fuera jefe de gobierno.
Figura 1. Reuniones de Vecinos por año. Desagregadas por autoridades presentes

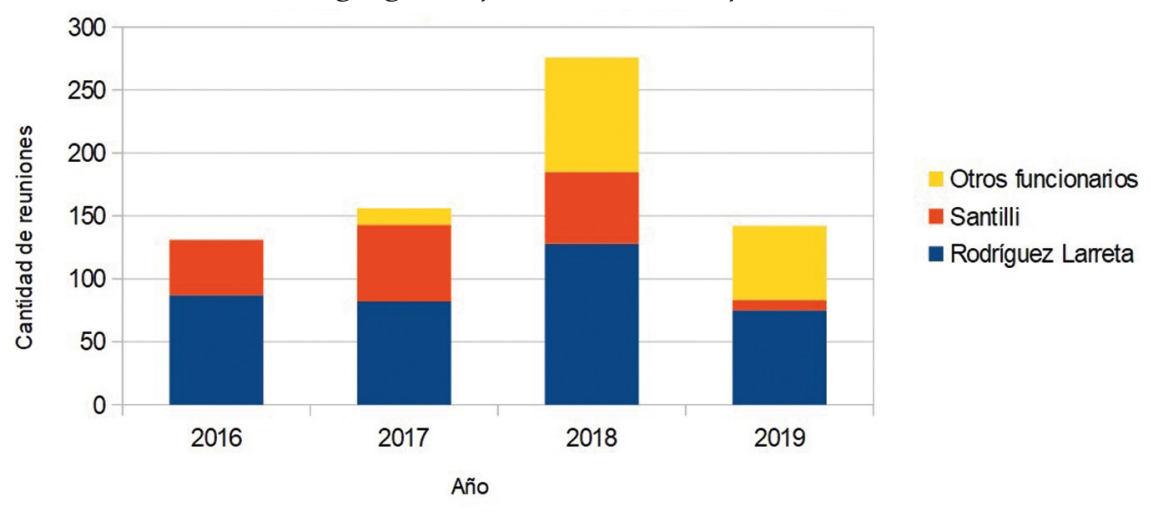

Fuente: Elaboración propia a partir de información del sitio oficial de Participación Ciudadana.

Para dimensionar esta práctica, es útil aportar algunos datos. De acuerdo con la información publicada en el sitio oficial de Participación Ciudadana, entre 2016 y 2019 primer gobierno de Rodríguez Larreta- se realizaron, en promedio, 176 reuniones de vecinos por año, aproximadamente una cada dos días (Cuadro 1). Rodríguez Larreta atendió al 53\% de ellas, y acudió -en promedio, anualmente- a 43 de los 48 barrios porteños. Por su parte, Santilli asistió al 24\% de las reuniones realizadas en el mismo período. ${ }^{3}$ Además, entre 2017 y 2018, Rodríguez Larreta participó, en total, en siete reuniones de vecinos en localidades de la provincia de Buenos, todas ellas gobernadas por el PRO.

A cada una de las reuniones observadas acudieron alrededor de 300 personas, aunque los encuentros con Santilli fueron menos concurridos que aquellos con Rodríguez Larreta. Sin embargo, a partir del cruce entre lo observado y la información consignada en el sitio oficial de Participación Ciudadana es posible deducir que la cantidad de asistentes varía notablemente según barrio, día y horario del evento. Por ejemplo, el sitio oficial consigna casos de reuniones con menos de 100 asistentes, por ejemplo, encuentros con Diego Santilli realizados un día de semana por la mañana.

La difusión de los eventos se efectúa por diversas vías, con aproximadamente una semana de anticipación. Estos son anunciados por el área de Participación Ciudadana en su sitio web oficial, Facebook y Twitter; además, se envían mails y se realizan llamados telefónicos a vecinos de la zona. También se difunde la información en las páginas de Facebook de Rodríguez Larreta y Santilli. En los días previos al encuentro también se realiza difusión en la vía pública en lugares aledaños al sitio de la reunión.

Una gran cantidad de funcionarios trabaja en la organización y el desarrollo de cada evento. Entre ellos, resalta la figura del moderador, rol que suelen ocupar legisladores, presidentes de juntas comunales (de comunas distintas a la del evento en cuestión) u otros funcionarios del GCBA. Es significativo que esa actividad la cumplan funcionarios políticos afines al PRO y, frecuentemente, del Poder Legislativo o Comunal antes que del Ejecutivo. Ello lleva a preguntarnos por la relación entre "acompañar" a Horacio Rodríguez Larreta en estas prácticas y el crecimiento político al interior del partido de quienes lo realizan. ${ }^{4}$ La presencia de legisladores y otros políticos en la moderación fue explicada por un funcionario de la Dirección de Cercanía en términos de "voluntad" y "ganas" por la participación. 
El desarrollo de las reuniones sigue un patrón prestablecido por la organización. Una vez al frente del auditorio, el jefe de Gobierno ${ }^{5}$ toma asiento y da inicio al evento haciendo algunos comentarios sobre éste y saludando a los vecinos. "Horacio", como es referido por el moderador y la folletería del evento, hace gala de un estilo descontracturado, vosea a los vecinos y les levanta el pulgar en señal de agradecimiento. Lo dicho por Rodríguez Larreta al comenzar las reuniones remite siempre a las mismas ideas, que son presentadas con frases muy similares. Retomaré ello más adelante, al referir al discurso en estos eventos. Cada reunión dura, puntualmente, una hora y media.

En las reuniones de vecinos se diferencian dos formas de participación: la interpelación directa al jefe de Gobierno y la presentación de "solicitudes" por medio de formularios.

Por medio del formulario, los participantes son nuevamente interpelados como vecinos por el GCBA, en esta ocasión, con el objetivo de "mejorar nuestra ciudad". Los formularios se concentran en reclamos puntuales: contemplan temas de mantenimiento urbano (arbolado, veredas, higiene). Mediante este dispositivo, las solicitudes son estandarizadas. El moderador del evento suele pedir a los participantes que en dichas solicitudes incluyan la calle y numeración en que se encuentra el problema, para mayor facilidad en su resolución. Una vez completados, los vecinos entregan los formularios a miembros de la organización.

Por otra parte, la forma de participación más pública consiste en dirigirse personalmente a la máxima autoridad de Gobierno de CABA. El moderador concede la palabra sucesivamente a distintos vecinos que se hubieran anotado para hablar. Además, éste solicita a los participantes que sean tan concretos y concisos como fuera posible, "para que podamos hablar todos". En algunas ocasiones, quien oficiaba de moderador solicitó que se utilizaran las intervenciones para hablar de cuestiones "que les interesen a todos", y reservar las cuestiones puntuales para los formularios. Dado lo numerosas que fueron las convocatorias registradas y la cantidad de asistentes que se inscribieron para hablar, en todos los casos la mayor parte de éstos no logró hacerlo.

Las únicas intervenciones válidas son las que se realizan al jefe de Gobierno cuando lo determina el moderador, y toda interacción por fuera de esa interpelación individual es disruptiva. Las interrupciones a las alocuciones de Rodríguez Larreta o de otros participantes son reprendidas por el moderador o, incluso, por "Horacio". De esta manera, los eventos no permiten las repreguntas porque, según indican los moderadores, darían paso a un "ida y vuelta interminable" y "todos quieren hablar".

En los eventos presenciados, todos ellos en la misma comuna, gran parte de los temas que fueron objeto de pregunta fueron los mismos. Algunos temas muy recurrentes fueron el estado de calles y veredas, la seguridad y los problemas de estacionamiento.

Luego de una serie de no menos de cinco preguntas, "Horacio" interviene para responder. Las intervenciones del jefe de Gobierno en el curso de cada reunión son alrededor de cuatro, contando la presentación inicial. Entre reunión y reunión es posible reconocer una serie de lugares comunes que son comunicados por el gobernante.

En dichas respuestas, Rodríguez Larreta explica en detalle las acciones del GCBA en torno a las problemáticas consultadas, de modo tal que evidencia sus conocimientos, tanto sobre las acciones de las distintas áreas de gestión, como sobre el territorio porteño. Esa demostración de saberes opera como una fuente de legitimación frente al auditorio. También es corriente la apelación a "historias" específicas de vecinos con los que, según indica, tuvo contacto recientemente.
5. Para hacer más fluida la escritura, referiré al jefe de Gobierno de $\mathrm{CABA}$, aunque las mismas prácticas son realizadas por el vicejefe de gobierno. 


\section{Discurso oficial en las reuniones de vecinos}

Los discursos desempeñan un papel central en la regulación moral (ver introducción). Respecto de ellos, Shore y Wright (1997) señalan que: "El lenguaje de la política pública y sus discursos proveen la clave para analizar la arquitectura de las relaciones de poder modernas" (p. 12). Y "los discursos son modos de pensar que pueden superponerse y reforzarse mutuamente y bloquear otras formas de pensar posibles. Definimos 'discursos' como configuraciones de ideas que proveen los tópicos a partir de los que se teje la ideología" (p. 18).

Considerando las múltiples recurrencias en las alocuciones de Rodríguez Larreta en las reuniones observadas, es pertinente abordar la construcción discursiva elaborada por las máximas autoridades del GCBA en estos eventos.

En su primera alocución, al inicio de la reunión, "Horacio" agradece la participación de los presentes y destaca que acude a reuniones en los distintos barrios "tres o cuatro veces por semana", ya que es fundamental para él mantener un contacto "cara a cara" con los vecinos. A su vez, apunta que "viene a escuchar a los vecinos" y no para hablar él, a lo que agrega que el objetivo es que le refieran sobre "lo que falta hacer y no sobre lo que ya hicimos", porque "lo que está bien, ya está". El contacto con las "historias" de los vecinos es mencionado como una fuente de "motivación" y "energía" para su labor como jefe de Gobierno. Además, hace hincapié en que "muchas propuestas e ideas surgidas en estas reuniones son luego tomadas para la gestión".

Esta noción de que el evento tiene por objetivo la gestión ("Hablemos de los temas bien concretos de la ciudad", "Hablemos de los problemas del barrio") y el hacer antes que la "política" (y la ideología) es reforzada indicando que no se trata de una "reunión política" ("No hagamos comentarios políticos") y separando el evento de la puja partidaria ("no me digan a quién votan"). Por último, Rodríguez Larreta también menciona que "no es necesario que estemos todos de acuerdo" y que "eso es la democracia".

De esta manera, son retomados desde el inicio del evento puntos clave de la racionalidad política del PRO, que serán recuperados continuamente en las intervenciones. Por un lado, ello se percibe en el énfasis en la cercanía con el vecino, devenido este sujeto en la forma hegemónica de referir al interlocutor del gobierno local por las distintas gestiones del PRO (Hernández, 2014). Esa noción de proximidad es presentada como valorizando el lugar del vecino, que es "escuchado" por la máxima autoridad del GCBA. A su vez, busca presentar la figura de Rodríguez Larreta como un "servidor". Al respecto, Vommaro y Morresi (2015) han destacado la noción de "la política como servicio" al interior del PRO.

Por otra parte, se destaca el foco en la gestión y el hacer antes que las posiciones ideológicas. Como señalan Vommaro y Morresi (2015, p. 14), "El PRO se define, según sus dirigentes, como un partido del hacer". Esta visión, tomada del mundo empresarial y del emprendedurismo, que privilegiaría la gestión, se presenta como pragmática, motivada por el hacer y concentrada en "seguir haciendo" antes que en hablar de "todo lo que ya hicimos".

Al respecto, vale la pena retomar a Vommaro y Morresi

[e] disfrute en el hacer, “Haciendo Buenos Aires”, es una forma de emprendedorismo que gobierna buena parte de la estética y la moral partidaria. Ese hacer es, al mismo tiempo, festivo [...] se liga precisamente a esta celebración de la vida plácida en una ciudad estetizada, sin violencia ni conflicto. [...] Más allá de la izquierda y la derecha, busca posicionarse como un partido que mira hacia adelante. (Vommaro y Morresi, 2015, p. 122) 
A su vez, aparece con fuerza la idea de gestión. Esta noción remite al gobierno como "solucionar problemas", limitado a la administración. Poggiese $(2009$, s.p.) considera que el PRO “opone el concepto de 'gestión', entendida como modo de gerenciar de forma empresarial al Estado, al concepto de 'política', explicada como el modo de gobernar sin eficacia y con corrupción".

Además, las reuniones de vecinos son encuadradas a partir de un tercer eje de la identidad PRO, atenta a lo "moderno" y el "futuro". La oposición entre viejo/nuevo estructura las intervenciones de Rodríguez Larreta y se relaciona con los otros ejes: la cercanía y el énfasis en el hacer y en la gestión (antes que en la ideología) son construidos como marcas que diferencian a la gestión PRO, posideológica, de la "vieja política" (Vommaro y Morresi, 2015). Mediante esta operación discursiva que cronologiza las diferencias ideológicas, el PRO se posiciona más allá de las contradicciones políticas. La pertenencia del adversario al "pasado" lo inhabilita y condena sus posiciones, al tiempo que el PRO se construye como el futuro. La construcción discursiva que ubica las acciones del GCBA más allá de las contradicciones políticas se observa en la idea de "mejorar la ciudad".

Una de las formas más explícitas que asume esta dimensión temporal en el discurso de las reuniones de vecinos es a partir de comentarios que enfatizan que ciertas políticas u obras del GCBA existen gracias a las gestiones del PRO ("cuando nosotros llegamos no había nada de todo esto").

A pesar de que al comenzar las reuniones "Horacio" refiere que la intención es hablar de "lo que falta hacer y no de lo que ya hicimos", en todas las ocasiones observadas las respuestas y comentarios del jefe de Gobierno derivaron en la mención a diversas obras y acciones que considera exitosas. Por ejemplo, en la comuna estudiada siempre señala que consiguieron expulsar a los manteros, lo que deriva en aplausos de buena parte del auditorio. Otras políticas de amplia aceptación por la población de CABA son apuntadas, aun cuando no fueran objeto de preguntas o comentarios por parte de los presentes; tal es el caso del Metrobus o de las luminarias LED, ambas justificadas por su superioridad técnica y asociadas a una "ciudad moderna".

También suele hacer referencia al reciclaje, remarcando la voluntad de los vecinos porteños de colaborar para tener una "ciudad verde". En dicho sentido, reivindica la política de las bicisendas y las "Ecobicis”, punto al que Rodríguez Larreta llega en ciertas ocasiones en sus respuestas a cuestionamientos al respecto, o en digresiones originadas en interpelaciones sobre vialidad o las dificultades para estacionar en el barrio.

Por otra parte, el jefe de Gobierno reserva invariablemente el final de las reuniones para hablar sobre la seguridad, tema al que califica como el "más importante" y "que más preocupa a los vecinos". Al respecto, refiere a las acciones de GCBA en la materia mencionando diferentes medidas, como la creación de la Policía de la Ciudad o los controles en coordinación con Provincia de Buenos Aires, ${ }^{6}$ entre otras. Al respecto, desliza que estas medidas no pudieron ser realizadas antes por falta de voluntad del Gobierno nacional o provincial en sus anteriores gestiones. Sin embargo, luego sitúa ello en el pasado y llama a trabajar hacia el futuro.

Como señalan Morresi y Vommaro (2015), por medio de la referencia a valores posmateriales el PRO se sitúa más allá de los ejes izquierda y derecha. Los autores señalan la importancia que juegan en esa estrategia la apelación a la seguridad y la presentación de "la idea de una nueva política pública orientada a la ecología con el objetivo de identificar la gestión de PRO con la idea de la CABA como 'ciudad verde”' (2015, p. 63).
6. Cabe recordar que el trabajo de campo fue realizado entre 2016 y 2017, período en que tanto la ciudad como la provincia de Buenos Aires estaban gobernadas por el PRO. 
Es decir, en las reuniones, Rodríguez Larreta menciona indefectiblemente políticas que están asociadas a la identidad partidaria del PRO, en algunos casos como respuesta a preguntas que le son formuladas, y en otras ocasiones mediante relaciones que él mismo traza en el curso de sus intervenciones.

La cercanía, aquí ejercitada por medio de las reuniones de vecinos, es significada como componente de la "nueva política" por oposición a otras formas de gobierno. Sin embargo, ello no necesariamente implica que la práctica en sí sea completamente novedosa; de hecho, remite en parte al llamado "gobierno de los barrios", desarrollado en Buenos Aires en el primer cuarto del siglo XX y que implicaba un vínculo directo entre funcionarios y vecinos (véase Landau, 2014).

\section{Otras iniciativas de BA Participación Ciudadana}

Con el objetivo de complementar o remarcar aspectos de la concepción oficial de participación y de la construcción de vecino que se realiza a través de ella, referiré a otras iniciativas del área de Participación Ciudadana. Al respecto, no seré minucioso en el relevamiento de las distintas prácticas ni en su descripción.

Lo que me interesa es señalar algunas continuidades entre las reuniones de vecinos y otras iniciativas participativas del GCBA, a saber: a) la participación como una charla individual -impulsada por el Poder Ejecutivo- entre el vecino con una autoridad del GCBA, sin deliberación ni decisión; b) el énfasis en la cercanía y la centralidad de la figura de Horacio Rodríguez Larreta y otros altos funcionarios en las iniciativas participativas; c) el carácter de evento de estas prácticas, sin continuidad entre encuentros ni regularidad; d) su funcionamiento no regulado por ley, dependiente exclusivamente de la voluntad del Poder Ejecutivo; e) la referencia a los habitantes de la Ciudad Autónoma de Buenos Aires como "vecinos" y "protagonistas".

En principio, quisiera detenerme un momento en dos breves textos del sitio web oficial de Participación Ciudadana en los cuales se sintetiza la visión oficial expresada sobre la participación ciudadana. Los reproduzco a continuación:

¿Sabés qué es participación ciudadana?

Participación ciudadana es un espacio para todos los vecinos. Para escuchar propuestas, compartir ideas que mejoren nuestra Ciudad y trabajar juntos para lograrlo. Todos podemos participar, porque la Ciudad somos todos los que la vivimos.

Participación Ciudadana

Un espacio de charla, de diálogo entre el vecino y el Gobierno de la Ciudad Autónoma de Buenos Aires.

Incentivamos la participación en todas las obras, iniciativas y eventos de cada barrio ¡Sumate y Participá!

(Fuente: http://bapc.buenosaires.gob.ar/)

En estos textos se evidencian aspectos salientes de la categoría nativa de participación del GCBA. En primer lugar, la definición como "espacio de charla" para "escuchar" y "compartir". Esta idea de "diálogo" presenta una noción de participación que, en principio, no tiene vínculo alguno con la capacidad de decidir o establecer iniciativas (al respecto, ese sentido que podría estar envuelto en "proponer" no lo está en "escuchar propuestas" ni en "compartir ideas"). Tampoco es presentada en vínculo con la rendición de cuentas por parte de los funcionarios.

Por otra parte, aquí la visión oficial señala los espacios creados como un "diálogo" cuyos interlocutores serían "el vecino y el Gobierno de la Ciudad de Buenos Aires". 
Ello es fundamental, ya que la participación implicaría así un vínculo individual del vecino (como sujeto político y en singular) con el GCBA. Se excluye en este texto la posibilidad de la deliberación/discusión entre vecinos, y con ello que la participación tenga un carácter organizado o colectivo.

Además, es relevante que se mencione "Incentivamos la participación", definiendo en qué consiste ella (en un diálogo con el GCBA), quiénes pueden participar ("todos los vecinos") y que se invite a los vecinos a "sumarse". Aquí la participación aparece como una iniciativa del Poder Ejecutivo; las prácticas del área de Participación Ciudadana no son reivindicadas en relación con los derechos de los ciudadanos de la CABA ni con los ámbitos estipulados por la normativa porteña. En ese sentido, el vecino como objeto de la política de participación se asocia menos a la noción de "sujeto titular de derechos" que a la de "beneficiario", que recibe la atención de un gobierno que elige escucharlo (Rofman y Foglia, 2015, p. 59).

Otro aspecto relevante está dado por la participación como ajena a controversias y discusión. Ello se refleja en la utilización del término "mejorar", también marcadamente presente en las reuniones de vecinos. La idea de "mejorar la Ciudad" ocluye discursivamente la perspectiva de distintas concepciones encontradas sobre qué es mejor; al fin y al cabo, la existencia de distintos intereses. Ello alimenta también la noción de unión de los vecinos como comunidad indiferenciada dada por una pertenencia territorial, y alienta la idea de que para "mejorar la Ciudad" es preciso "trabajar juntos". Estas nociones también remiten directamente a la construcción discursiva del PRO. Por ejemplo, "Juntos venimos bien", "Juntos podemos", "Un equipo con 3 millones de vecinos", "Vamos juntos" y "Juntos podemos más" fueron los slogans de campaña de este partido en las elecciones en CABA en 2011, 2013, 2015, 2017 y 2019 respectivamente.

Por último, es de notar la utilización de la segunda persona en la apelación al vecino. Esta voz está extendida por todo el sitio web y da cuenta de una forma específica, no solo individual, sino pretendidamente personal de construir el vínculo entre el GCBA y los vecinos.

En todo caso, es clave observar la sintonía entre la concepción enunciada de participación y las prácticas concretas que son desplegadas en las iniciativas participativas del GCBA, tales como las que aquí analizo.

Algunos de estos aspectos también pueden ser apreciados en otras modalidades de participación, tales como los "Desayunos con Horacio", las "Reuniones de Relevancia", "Reuniones con Ministros" y las votaciones y concursos online; todas prácticas difundidas a través del sitio oficial de Participación Ciudadana y páginas de Facebook y Twitter.

Los "Desayunos con Horacio" son referidos en la página con la siguiente información:

Todas las semanas Horacio se junta a desayunar con vecinos, para charlar y escuchar sus ideas y sus sueños. La opinión de cada vecino es importante y permite saber en qué venimos bien y qué es lo que todavía hay que mejorar.

Cada desayuno luego es objeto de una entrada en el sitio web, en la cual, desde una primera persona situada en Rodríguez Larreta, se incluye un breve comentario biográfico sobre los anfitriones, el encuentro y cómo las historias de los vecinos motivan al jefe de Gobierno. El texto es acompañado por fotos del encuentro en las que se ve a Rodríguez Larreta y a los vecinos sonriendo, tomando mate y conversando en forma distendida. 
Esta "práctica participativa" parece tener menos el foco en el encuentro en sí que en su difusión, en tanto proyecta una forma de relación específica entre el jefe de Gobierno y el vecino anfitrión, marcada por un trato personal, cercano al nivel de lo "doméstico".

Con una lógica similar, en 2016 fue lanzado el programa "Corré con Horacio", el cual ofrecía la posibilidad de hacer ejercicio matutino con el jefe de Gobierno. Sin embargo, fue discontinuado en 2017.

Respecto de las "Reuniones de Relevancia", en estos eventos, el jefe de Gobierno y un "especialista" se reúnen para tratar sobre un tema específico con un auditorio que tiene la posibilidad de realizar preguntas al respecto. Estos encuentros tienen una frecuencia mensual. Según registra el sitio oficial de Participación Ciudadana, entre enero de 2016 y diciembre de 2019 fueron realizadas 51 reuniones de relevancia, en 34 de las cuales intervino Rodríguez Larreta. Los "especialistas" convocados suelen ser personalidades de presencia mediática, por ejemplo, Nicole Neumann, Beto Casella y Cris Morena. Ocasionalmente, en un evento sobre educación participó la ministra de Educación de CABA.

Por su parte, la dinámica de las Reuniones con Ministros es prácticamente igual a la de la reuniones de vecinos, aunque están recortadas temáticamente al área del ministro presente.

Tanto en las reuniones de vecinos, como en los Desayunos, Reuniones de relevancia y con Ministros, las máximas autoridades de CABA tienen una centralidad excluyente en la participación.

Con respecto a las votaciones online, los tópicos sobre los que votar, así como las opciones, son presentados por el GCBA. Los medios preferidos para llevar adelante las votaciones son Facebook y Twitter, es decir, canales no oficiales.

Los tópicos votados tienen que ver con a) dónde se realizará un evento; b) características de un evento próximo a realizar; c) características de diseño urbano (murales, accesorios en plazas); o d) cambio de regulaciones. Este último tipo de votaciones comenzó a aparecer en el año 2017, y plantea opciones de sí o no. Algunas de las consultas realizadas fueron sobre permitir mascotas en restaurantes y permitir mascotas en subtes.

A su vez, en la misma sección del sitio web se incluye la participación en concursos y eventos, tales como sorteos de entradas para espectáculos. Esta forma de participación está presente en la página oficial de Participación Ciudadana y en su Facebook en forma recurrente.

La constante apelación a esta noción de participación remite a los lemas empleados por el GCBA, tales como "En todo estás vos" y "Disfrutemos BA”. Así se refuerza la apelación a los vecinos como "protagonistas" (Hernández, 2014). Esta idea de "protagonismo" también fue invocada por el jefe de Gobierno en su discurso de asunción ante la Legislatura, cuando señaló:

Cuando fui Jefe de Gabinete me reuní con vecinos de todos los barrios de la Ciudad, porque estoy convencido de que ellos son los verdaderos protagonistas y los que saben mejor que nadie qué es lo que hace falta para mejorar la Ciudad en la que vivimos. 


\section{Moralización de la política y regulación moral}

Antes de adentrarnos en el análisis de las prácticas de participación promovidas por el GCBA como vías por medio de las cuales se realiza un proceso de regulación moral, resulta imprescindible atender cómo son entendidos aquí los vínculos entre moralidad y política.

Siguiendo a Frederic (2004, p. 40), "la moralidad está entretejida con la política de manera que, sólo considerando a ambas, la práctica de los políticos se vuelve inteligible". Para comprender esa conjugación, la autora propone abordar la "moralidad como práctica”, ya que las evaluaciones morales están animadas por un sentido práctico. En forma simétrica, se puede decir que la praxis política está, de por sí, moralmente informada, ya que la moral es parte de la cognición (Balbi, 2011). Así, la moralidad es una instancia constitutiva de las relaciones de poder. Es clave apuntar que la elección entre distintas evaluaciones morales es posible.

A los fines del presente abordaje, resulta esencial recuperar lo planteado por Sabina Frederic:

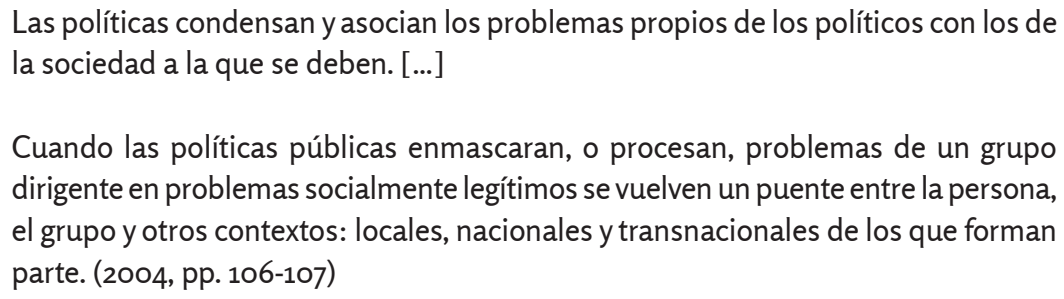

Planteado esto, aquí propongo que, a partir de las iniciativas de participación, el gobierno del PRO conecta las necesidades de su grupo dirigente con tópicos que son construidos como problemas sociales. Este proceso implica, simultáneamente, la moralización del ejercicio de gobierno en forma acorde con la racionalidad política y la identidad partidaria, la regulación del crecimiento político y la definición de una comunidad de referencia (Frederic, 2004).

Mediante estas prácticas se lleva adelante una "regulación moral" que normaliza ciertas formas específicas de gobierno y de participación, y apela a una comunidad imaginada de referencia específica, obstruyendo el camino para la concepción y ejercicio de otras formas. A su vez, esta regulación moral, ligada al proyecto político del PRO, se encuentra en interacción (y disputa) -en distintas escalas- con proyectos políticos alternativos.

Entonces, la participación, sello de la gestión Rodríguez Larreta, forma parte de la “moralización PRO” del gobierno: aquí el gobierno como política se contrapone al gobierno como gestión. El "gobierno político" aparece como corrupto, ineficaz, "ideológico”, conflictivo (Poggiese, 2009; Hernández, 2014). Por su parte, la gestión sería cercana, centrada en el hacer, y responde a los intereses de los vecinos. En cierto modo, la gestión se presenta como defendiendo el gobierno del sentido común, frente a lo "ideológico".

En ese sentido, la política de participación del GCBA se inserta dentro de esta concepción de la gestión, en un vínculo dinámico. Como señalan Rose y Miller (1992, p. 181), "la relación entre racionalidades políticas y programas de gobierno no es de derivación o determinación, sino de translación”. Así, antes de adentrarme en la participación o la producción de ciudadanía, vuelvo un momento a los valores morales reivindicados por el PRO, con los que aquellas dialogan. 
7. Por ejemplo, para Marcelo, presidente de la junta comunal estudiada, la proximidad a Larreta parece ser un valor preciado. Tras cada actividad en que tiene posibilidad de mostrarse públicamente con "Horacio" (Reuniones de vecinos, caminatas de campaña por la calle, etc.), carga imágenes de ambos en su página de Facebook. De hecho, la foto de perfil de Facebook de Marcelo es de un evento que compartió con Larreta, y se lo ve en primer plano al jefe de Gobierno y, en segundo plano, a Marcelo.
A lo largo del artículo he dado cuenta de valores morales propios de la identidad partidaria del PRO. Recuperando la clasificación hecha por referentes de dicho partido en el documento Nuestra Idea (firmado, entre otros, por Gabriela Michetti, Federico Pinedo, Alejandro Rozitchner e Iván Petrella):

Nuestra identidad tiene tres dimensiones:

- la cercanía (la empatía, mirar la realidad desde el punto de vista del otro, determina desde dónde hacemos política),

- la positividad (el hacer transformador, el para qué hacemos política)

- el futuro (la dimensión temporal o la visión).

Estas tres dimensiones aparecen en forma patente en las reuniones de vecinos. A su vez, la proyección del PRO como un partido con estos valores excede en mucho la experiencia de las políticas de participación; permea toda la comunicación partidaria y de difusión estatal del GCBA. En la práctica de las reuniones de vecinos, estas dimensiones se presentan tanto discursivamente como materializadas en aspectos específicos.

La cercanía, categoría que en la actualidad incluso designa una Dirección General del GCBA, se materializa en la proximidad asumida por los funcionarios de gobierno, quienes "escuchan a los vecinos" y están presentes en los barrios "dialogando" con ellos. La cercanía también aparece en el trato informal que dispensa el jefe de Gobierno.

En el marco de las reuniones de vecinos, la dimensión de "positividad" aparece más claramente bajo la categoría de hacer. La gestión es el objetivo de las reuniones; las solicitudes y demandas de los vecinos son registradas mediante los formularios y de la interacción directa con los funcionarios. Discursivamente, Rodríguez Larreta hace gran hincapié en explicar las acciones realizadas por las distintas áreas del GCBA, y ese hacer es significado como un elemento de "satisfacción" por el jefe de Gobierno porteño, quien señala que "ver las cosas que le cambian la vida a la gente" le "motiva a seguir haciendo".

Con respecto a la dimensión de "futuro", como fue explicitado previamente, el eje viejonuevo se presenta estructurando el discurso en las reuniones de vecinos.

Estas dimensiones, de carácter profundamente moral, en la práctica están estrechamente ligadas a la noción de gestión impulsada por el PRO. Cabe resaltar que los mensajes propios de las reuniones de vecinos no solo son transmitidos mediante el discurso. Existen diversos aspectos formales (como las formas de participación, la organización de los tiempos, espacialidad, gestualidad) que reiteran y refuerzan las mismas nociones de cercanía y el énfasis en el hacer.

Previamente señalé que por medio de las iniciativas de participación se lleva adelante una moralización de la política que busca vincular las necesidades de un grupo dirigente con tópicos construidos como "problemas sociales legítimos". Por un lado, por medio de la participación, el gobierno del PRO encuentra una vía para regular el crecimiento político, disponer de presencia territorial y reforzar (y redefinir) la comunidad de referencia a la que apela. Las reuniones favorecen el crecimiento político, tanto del jefe y vicejefe de Gobierno y ministros -que aquí construyen sus figuras como referentes del PRO en la CABA, lo que les permitiría proyectarse a otros ámbitos-, como de los legisladores y presidentes de juntas comunales que "acompañan" los funcionarios y así tienen la posibilidad de mostrarse. ${ }^{7}$ 
Por otro lado, las reuniones de vecinos, así como otras políticas de participación del GCBA, conectan con la "necesidad" de los vecinos de ser escuchados y de una gestión eficiente y desideologizada, valores asociados a "la nueva política”. Así, se resalta continuamente que las ideas de los vecinos son utilizadas para la gestión y que existe una gran voluntad de protagonismo por parte de ellos, quienes participarían masivamente en los eventos.

Además, las reuniones se relacionan con una forma específica de concebir la territorialidad de Buenos Aires. Si bien el PRO no carece de presencia territorial, el fuerte de la comunicación partidaria se concentra en medios de comunicación masiva y redes sociales. Por ello, a menudo se ha definido al PRO como un partido de audiencias (Vommaro, Morresi y Bellotti, 2015).

Sin embargo, la relación de los dirigentes del PRO con la territorialidad de la CABA refleja ciertas diferencias internas. Al respecto, resulta especialmente interesante evocar extensamente lo referido por Vommaro y colaboradores, en diálogo con Gabriela Michetti:

Desde sus comienzos, PRO trabaja su imagen mediática en detalle. Casi se podría decir que las nuevas tecnologías y la publicidad política constituyen una estrategia central de este partido nuevo, que encuentra así la posibilidad de llegar adonde sus redes partidarias no alcanzan, en un distrito -por otra parte- en el que la relación con la política no se presenta de modo prioritario en los vínculos cara a cara. "En la ciudad de Buenos Aires no se requiere construcción territorial, sí en el interior del país, al igual que en el conurbano", dijo Michetti cuando le consultamos sobre la posibilidad de disputar la candidatura a la jefatura porteña con Rodríguez Larreta, quien sí considera necesario poner el cuerpo en la calle. Para nuestra sorpresa, la dirigente reforzó la idea de la siguiente manera: "La ciudad de Buenos Aires es una ciudad absolutamente mediática, pendiente de los medios, el Facebook, Twister [sic]... iMauricio nunca hizo construcción territorial! Entonces les pregunto: la construcción territorial de (Rodríguez) Larreta, ¿dónde está?”. (2015, p. 138)

Como fue señalado, las reuniones de vecinos y las reuniones con ministros aseguran una presencia, no constante pero sí regular, de referentes del GCBA en los distintos barrios, en contacto cara a cara con los vecinos. Se podría pensar en la relación entre esta práctica con otras modalidades de intervención territorial del PRO, como los "timbreos", que no solo son realizados en momentos de campaña electoral (Vommaro y Morresi, 2015; Vommaro et al., 2015).

Estas prácticas pueden ser relacionadas con una táctica conocida como "campaña permanente", consistente en "transpolar las técnicas de marketing político y la opinión pública de las campañas electorales a las acciones de gobierno". Por medio de esta, los políticos del PRO optimizan los frutos rendidos por cada acto y obra en "términos de imagen pública y performance electoral” (Vommaro et al., 2015, p. 152).

Sin embargo, al referir estas operaciones no sugiero que la participación sea una "puesta en escena". Si bien los eventos no estan despojados de interés y cálculo, también en términos electorales, dan cuenta de las formas en que la política, el gobierno y el contacto con la población son entendidos por el PRO.

\section{Gobierno como 'gestión cercana'}

En las reuniones, "Horacio" vincula la cercanía a una serie de valores morales, tales como la empatía y la humildad. En ocasión de una reunión de relevancia también relacionó dichos valores con su preferencia por ser nombrado "Horacio" antes que 
por su cargo de jefe de Gobierno. Más aún, hizo hincapié en su vínculo próximo a la población distanciándose del cargo oficial "A mí, cuando me hablan de jefe de Gobierno... yo soy intendente". A continuación, definió su trabajo nuevamente en clave de proximidad, al considerar que "la ciudad es como un gran consorcio, yo tengo que solucionar los problemas".

A pesar de que la figura de "Horacio" en todo momento se diferencia de los vecinos, Rodríguez Larreta busca asociar la gestión cercana a un vínculo personal con ellos, al tiempo que derriba simbólica y espacialmente las barreras que los separan. Esta elaboración puede asociarse con lo apuntado por Landau y Annunziata (2017), "la proximidad [...] es un tipo de vínculo representativo que se legitima con la idealización de la política local: los ciudadanos ideales son 'vecinos', y los políticos ideales, actúan como se supone que actuaría un intendente".

Por otra parte, como señala Slimovich (2017), la personalización y el personalismo de la política adquieren un nuevo giro a partir de la expansión de las redes sociales. En el caso de las iniciativas de participación del GCBA se observa que, en algunas de ellas (tales como los desayunos), la interacción vía Facebook, por ejemplo, ocupa un lugar primordial.

Mediante la personalización del vínculo de las autoridades del GCBA con los representados se reconfiguran las representaciones de la espacialidad del Estado. Por medio de las reuniones de vecinos se refuerzan las metáforas espaciales de "verticalidad" y "abarcamiento" en la concepción del funcionamiento del Estado (Ferguson y Gupta, 2002). A través de estas metáforas socialmente efectivas, el Estado es concebido como una institución por encima de la sociedad y ubicado en una escala que comprende a los diversos individuos y agregados dentro de un territorio.

Sin embargo, esa espacialidad representada de verticalidad y abarcamiento asumen aquí una nueva forma: ya no se manifiesta a través de una serie de instituciones que median entre la "cabeza" del Estado porteño y cada vecino, sino que el individuo interactúa en forma directa, individual y personal con la máxima autoridad de la ciudad.

Naturalmente, esta representación del Estado porteño coexiste, y es secundaria, con otras que sí conciben una serie de mediaciones entre los individuos y la Jefatura de Gobierno de CABA. La efectividad social de esta construcción reside en que, a la vez que se representa cierto funcionamiento del GCBA y del rol de los vecinos, se produce una imagen específica de Rodríguez Larreta. Dicha representación movilizada en las reuniones de vecinos busca asociar a "Horacio" a los valores de transparencia y proximidad con ellos. Pretende presentarlo como abierto al diálogo, legitimado por sus conocimientos de la ciudad, preocupado por gestionar con eficiencia (no por discutir "posiciones ideológicas") y favorable a la participación ciudadana. Con estas prácticas participativas basadas en la "charla cara a cara", los referentes del PRO en la CABA intentan legitimarse, favoreciendo una aproximación empática que los diferenciaría de otros dirigentes políticos que solo son vistos a través de medios masivos de comunicación o en actos de campaña electoral.

\section{Participación como 'ser escuchado'}

Respecto de la participación impulsada por el Poder Ejecutivo porteño, previamente fue destacada su concepción como "charla" individual entre el vecino con el GCBA, que es el impulsor de ese "diálogo" en que se pretende "mejorar la ciudad", planteado al margen de conflictos y controversias. 
Las políticas de participación mencionadas no están reguladas por ley, por lo que los espacios no tienen competencias definidas y su convocatoria depende exclusivamente del Poder Ejecutivo, tanto en sus formas, como en sus tiempos y recursos. Ello es contrastante con otros órganos de participación existentes en CABA, tales como los Consejos Consultivos Comunales, previstos por la Constitución de la Ciudad y regulados por la Ley 1.777. Además de ello, la Constitución de la Ciudad de Buenos Aires contempla la participación ciudadana en diversas áreas de planificación y gestión (Arts. $21 ; 24 ; 27 ; 32 ; 34 ; 38 ; 40 ; 52$, entre otros). De hecho, el Art. 1 establece que la Ciudad "organiza sus instituciones autónomas como democracia participativa".

Sin embargo, las iniciativas participativas impulsadas por el gobierno del PRO no son reductibles a ningún mecanismo prefigurado en la Constitución y no se presentan como un derecho de la ciudadanía, sino como la voluntad de un gobierno que "escucha a los vecinos". Al respecto, los participantes no tienen incidencia en las formas que asume dicha participación, ni en los recursos que ella moviliza. Más aún, en estas políticas raramente son puestos en discusión recursos económicos, al menos abiertamente.

Las reuniones de vecinos, así como el resto de las modalidades de participación del GCBA, se plantean abiertas a cualquier individuo, con la única condición de su pertenencia territorial al barrio. De este modo, los vecinos son la comunidad imaginada de referencia de estas políticas, y el vecino aparece como el sujeto político "no-político" de la Ciudad de Buenos Aires.

En las iniciativas participativas del GCBA, los vecinos interactúan en forma individual y directa con el funcionario; la deliberación entre vecinos no solo no es alentada sino que implica una disrupción del desarrollo de la reunión. Este carácter individual, sumado a que los eventos de participación son convocados desde el Poder Ejecutivo a voluntad (sin regularidad) y que son independientes unos de otros (sin continuidad), torna improbable que la política derive en organización por parte de los concurrentes.

El hecho de que la participación sea realizada individualmente, sin mediar deliberación ni organización, favorece una presentación temática por parte de los vecinos que se limita a su experiencia individual antes que a dar cuenta de procesos o problemáticas más amplias. Ello estaría en línea con la construcción de vecino, sujeto político interpelado por la gestión PRO, según la cual éstos estarían preocupados en forma exclusiva por "problemas concretos y cotidianos", y legitimados por "un saber vivencial no distorsionado ideológicamente" (Hernández, 2014, p. 7). En ninguna instancia de los eventos se produce una votación o un consenso entre los participantes: la ponderación de los diversos planteos realizados recae únicamente en la apreciación de los funcionarios del GCBA. Este enfoque presente en la mayoría de las intervenciones en reuniones de vecinos también se asimila a lo perseguido por medio de los formularios de participación, donde se alienta la manifestación de "solicitudes" puntuales.

Estas prácticas, por las cuales se realiza una regulación moral que normaliza formas específicas de participación, son complementarias de otras acciones que excluyen otras modalidades de participación alternativas. Tal es el caso de los Consejos Consultivos, previstos en la Constitución de CABA y regulados por ley, pero deliberadamente desincentivados por el PRO a lo largo de sus gobiernos (Coto, 2018).

\section{Ciudadanos como 'vecinos participativos'}

En sus sucesivos gobiernos, el PRO ha definido a los vecinos como su comunidad de referencia, tanto para la formulación de políticas y para la apelación en contextos electorales. Como señala Hernández (2014, p. 3), 
[l]a categoría de vecinos, lejos de restringirse a la dimensión de la proximidad espacial y eventualmente vincular de habitantes de un barrio, devino progresivamente un operador capaz de delimitar al habitante medio de la ciudad y, más aún, al legítimo interlocutor de las autoridades locales.

De esta manera, el concepto de vecino se asocia a otros significados distintos que el del mero "habitante" de la ciudad. Dicha noción permea a los sujetos a través de los discursos y las prácticas del Gobierno de la Ciudad (por ejemplo, las diversas modalidades de participación), los produce como sujetos preocupados en forma exclusiva por "problemas concretos y cotidianos", poseedores de un saber vivencial no distorsionado ideológicamente. En tanto tales, es a estos a quienes los funcionarios "deben aproximarse para encontrar soluciones a los problemas -sinónimo de gobernar la ciudad-” (Hernández 2014, p. 7, destacado en el original). En esta línea, la categoría de vecino producida desde el Gobierno de la Ciudad (y los discursos del PRO) remite a la idea de gobierno como gestión, ajena a la ideología y centrada en el hacer para "mejorar la ciudad".

Más aún, dicha participación abona una concepción fragmentaria de la ciudad y los sujetos que la habitan. Las reuniones de vecinos que se realizan en los distintos barrios convocan al jefe de Gobierno a discutir sobre ese ámbito microlocal, en el cual los vecinos están legitimados por su experiencia directa. Es decir, el barrio es el territorio de expertise de los "vecinos participativos", no la ciudad.

Esta construcción del sujeto político no es completamente novedosa y quizás por ello haya resultado efectiva para el PRO. Si bien la Ciudad de Buenos Aires tiene un profundo vínculo con la política nacional, en tanto localidad fue históricamente concebida como un espacio no conflictivo, y su gobierno se pensó relacionado con un "ideal técnico, ligado a la resolución de aspectos vinculados con la vida urbana" (Landau, 2015, p. 76). Bajo esos ejes, la noción de vecinos fue históricamente prioritaria para dar cuenta del colectivo que conforma la ciudad de Buenos Aires, aunque con distintos sentidos según el momento histórico (Landau, 2014).

En su sentido de pertenencia territorial, vecino "imagina" a esa comunidad de referencia como indiferenciada hacia su interior y diferenciada hacia quienes no pertenecen a la CABA. Por medio de dicha categoría se define, o pretende definir, a los legítimos usuarios de los servicios de la Ciudad de Buenos Aires. Así, se establece una distinción respecto de los individuos del conurbano bonaerense y del resto del país (o, incluso de fuera de él) que utilizan recursos de la ciudad. Esta concepción de vecino surge con más vehemencia en los discursos de los participantes de las reuniones de vecinos, quienes frecuentemente critican la utilización gratuita del servicio de salud porteño por parte de personas que no residen en la ciudad. En este punto, la categoría es asociada con el pago de impuestos en la jurisdicción (Hernández, 2014). Aunque menos airado, "Horacio" también relaciona la afluencia de personas del conurbano con problemas de estacionamiento, tránsito y en los servicios de salud, aclarando que la ley avala la atención médica a todos.

Por otra parte, la noción de vecino tiene otra dimensión por la cual estos son representados como "vecinos protagonistas" (Hernández, 2014). Esta categoría analítica propuesta por Hernández parece encontrar su reflejo en el campo en la noción de "vecino participativo", utilizada por diversas agencias estatales para saludar a la población porteña en el "Día del vecino participativo".

\section{¡FELIZ DÍA A TODOS LOS VECINOS PARTICIPATIVOS!}

La Ciudad la construimos entre todos y hoy queremos agradecerles por ser una parte fundamental en la transformación que realizamos día a día para que todos 
podamos disfrutarla más.

Esta idea de protagonismo o participación como "celebratoria" -que excede a la categoría de "participación ciudadana" como una forma de praxis política-, permite acercarnos a la noción de participación asociada a concursos por entradas a eventos culturales, también movilizada desde el área de Participación Ciudadana de CABA.

Sin embargo, en cuanto sujetos políticos, los vecinos participan en modalidades altamente reguladas, en las que los sujetos no deciden, ni deliberan, ni tienen incidencia en las formas y contenidos de lo que puede ser objeto de participación.

\section{A modo de cierre}

A lo largo del artículo analicé las modalidades de participación impulsadas por el GCBA como prácticas por las cuales se lleva adelante una regulación moral por la cual ciertas formas específicas de gobierno, participación y ciudadanía son normalizadas.

En este proceso, el gobierno del PRO realiza simultáneamente una regulación moral de dichos aspectos en términos afines a su propia racionalidad partidaria y procesa las necesidades de sus dirigentes en términos que le permiten conectarlas con tópicos construidos como problemas sociales. Esto es, además de lo intrínsecamente ligado a regulación moral, por medio de la participación el PRO a) regula el crecimiento político de sus dirigentes; b) realiza su construcción territorial; y c) refuerza y redefine la comunidad de referencia a la que apela y, con ello, la relación entre gobernantes y gobernados.

\section{Financiamiento:}

Este documento es resultado del financiamiento otorgado por el Estado Nacional, por lo tanto, queda sujeto al cumplimiento de la Ley № 26.899. La investigación que sirvió de base al texto ha sido parcialmente financiada por la Universidad de Buenos Aires en el marco de la Programación UBACyT 2018-2020. Cód.: 20020170100644BA. Título del proyecto: "Producción social y valorización en los procesos políticos. Un análisis antropológico”.

\section{Agradecimientos:}

Agradezco a Fernando Balbi por sus comentarios, que enriquecieron el presente artículo; también a Brenda Canelo, por su orientación en la investigación que le dio origen.

Gracias a los/as comentaristas por sus observaciones. Algunas de las valiosas sugerencias que realizaron no pudieron ser incorporadas en el texto por razón de espacio. Sin embargo, espero recuperarlas en futuras publicaciones.

\section{Biografía}

Joaquín Coto es Licenciado en Antropología Social por la Universidad de Buenos Aires. Actualmente es becario doctoral UBACyT en la Universidad de Buenos Aires y maestrando en Antropología Social en la Universidad de Oslo 


\section{Q Referencias bibliográficas}

» Balbi, F. (2011). Sobre la orientación moral del comportamiento y los usos prácticos de las orientaciones morales. En X Congreso Argentino de Antropología Social, GT 39: Antropología de las moralidades. Facultad de Filosofía y Letras, UBA, Buenos Aires, Argentina.

» Corrigan, P. y Sayer, D. (2007 [1985]). El gran arco: La formación del Estado inglés como revolución cultural. Introducción y posdata. En M. Lagos y P. Calla (comps.), Antropología del Estado. Dominación y prácticas contestatarias en América Latina. La Paz: Informe Nacional sobre Desarrollo Humano, Programa de las Naciones Unidas para el Desarrollo.

"Coto, J. (2018). Participación, Ciudadanía y Comunas: Disputas en torno a la descentralización de la ciudad autónoma de Buenos Aires. (Tesis de licenciatura), Facultad de Filosofía y Letras, Universidad de Buenos Aires, Buenos Aires, Argentina.

» Ferguson, J. y Gupta, A. (2002). Spatializing states: toward an ethnography of neoliberal governmentality. American Ethnologist, 29, 981-1002.

» Frederic, S. (2004). Buenos vecinos, malos políticos: moralidad y política en el Gran Buenos Aires. Buenos Aires: Prometeo.

» Hernández, S. (2014). Los vecinos del vecindario al protagonismo. Un aporte comunicacional para pensar los procesos urbanos. Avatares, 7 (junio), 1-17.

" Landau, M. (2014). La ciudad y sus partes: una historia de la institucionalidad local en la Ciudad de Buenos Aires. EURE, 4O(119), 151-171.

» Landau, M. (2015). No sólo de globos vive el PRO. El macrismo en la larga tradición del gobierno de la ciudad. Revista Ciencias Sociales, 87, 74-79.

» Landau, M. y Annunziata, R. (2017). ¿Qué hay de nuevo en el timbreo?. Revista Anfibia. Recuperado de: http://revistaanfibia.com/ensayo/que-hay-de-nuevo-en-timbreo/

»Poggiese, H. (2009). Programa de transición para las comunas de la ciudad de Buenos Aires: una historia de nunca acabar. Mundo Urbano, 34. Recuperado de: http://www. mundourbano.unq.edu.ar/index.php/ano-2009/15-numero-34/211-programa-de-transicion-para-las-comunas-de-la-ciudad-de-buenos-aires-una-historia-de-nunca-acabar

» Rofman, A. y Foglia, C. (2015). La participación ciudadana local en la historia argentina reciente (de los '9o a la actualidad): Asistencia, movilización, institucionalización. Estado y Políticas Públicas, 5, 41-61.

» Rose, N. y Miller, P. (1992). Political Power beyond the State: Problematics of Government. The British Journal of Sociology, 43(2) (junio), 173-205.

» Shore, C. y Wright, S. (1997). Policy: A new field of anthropology. En C. Shore y S. Wright (Eds.), Anthropology of Policy. Critical perspectives on governance and power. Londres y Nueva York: Routledge.

»Slimovich, A. (2017). La ruta digita a la presidencia argentina. Un análisis político e hipermediático de los discursos de Mauricio Macri en las redes sociales. Dixit, 26 (enerojunio), 24-43.

»Vommaro, G. y Morresi, S. (orgs.) (2015). Hagamos equipo: Pro y la construcción de la nueva derecha en Argentina. Los Polvorines: Universidad Nacional de General Sarmiento.

» Vommaro, G. y Morresi, S. y Bellotti, A. (2015). Mundo PRO. Buenos Aires: Planeta. 


\section{Otras fuentes consultadas}

》Dirección General de Estadísticas y Censos del Gobierno de la Ciudad de Buenos Aires (2019). Anuario Estadístico 2018. Ministerio de Economía y Finanzas de la Ciudad Autónoma de Buenos Aires

"Constitución de la Ciudad Autónoma de Buenos Aires. Recuperado de http://www.infoleg.gob.ar/?page_id=166

"Discurso de asunción de Horacio Rodríguez Larreta como Jefe de Gobierno, 11/12/2015. Recuperado de https://www.buenosaires.gob.ar/noticias/discurso-de-asuncion-deljefe-de-gobierno-horacio-rodriguez-larreta

"Sitio oficial del área de Participación Ciudadana del Gobierno de la Ciudad Autónoma de Buenos Aires. http://bapc.buenosaires.gob.ar/ 